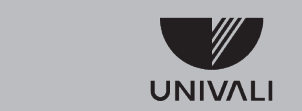

UNIVERSIDADE DO VALE DO ITAJAí

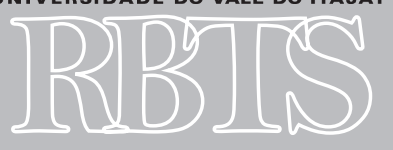

Revista Brasileira de Tecnologias Sociais
1 Mestre em Enfermagem pela Universidade Federal de Santa Catarina. Doutoranda em Enfermagem pela Universidade Federal de Santa Catarina. Professora do Instituto Federal de Educação, Ciência e Tecnologia de Santa Catarina.jujdacosta@gmail. com.

2 Graduando em Nutrição pela Universidade do Vale do Itajaí. mu.lyra@gmail.com

3 Doutora em Enfermagem pela Universidade Federal de São Paulo.

4 Doutora em Saúde Coletiva pela Universidade Federal de Santa Catarina. Professora do Curso de Odontologia e do Programa de Pós-Graduação do Mestrado em Saúde e Gestão do Trabalho da Universidade do Vale do Itajaí. rita.lima@univali. br

5 Doutora em Enfermagem pela Universidade Federal de Santa Catarina Professora do Departamento de Saúde Coletiva e do Programa de PósGraduação em Saúde Coletiva da Universidade Federal de Santa Catarina.marta.verdi@ufsc.br
Revista Brasileira de Techologias Sociais, v.3, n.1, 2016

\section{Questões éticas implicadas no cuidado a gestantes portadoras de HIV}

\section{Ethical issues in the care of pregnant women with HIV}

\author{
Juliana Jacques da Costa ${ }^{1}$; Murilo Lyra Pinto $^{2}$; Elisete Navas Sanchez \\ Prospero $^{3}$; Rita de Cássia Gabrielli Souza Lima ${ }^{4} \&$ Marta Verdi $^{5}$
}

RESUMO: Pesquisa qualitativa realizada com o objetivo de conhecer eventuais implicações éticas geradas no processo de cuidado de gestantes soropositivas em um contexto distrital de uma cidade catarinense de médio porte. Os dados revelaram ausência de um sistema de referência e contrarreferência suficientemente denso para garantir o cuidado integral; negação das dimensões humanísticas e fisiológicas na condução do cuidado; presença de processos discriminatórios; limitação na produção de fluxos éticos da rede de atenção; submissão do direito à narrativa e uma trajetória de exclusão do direito constitucional de garantia da inviolabilidade da vida privada. A pesquisa faz um chamado para a necessidade de a dimensão ética do cuidado ser assumida na rede de atenção como uma tecnologia relacional.

PALAVRAS-CHAVE: ética; gestantes de alto risco; referência; contrarreferência; redes de atenção; tecnologia relacional.

ABSTRACT: This is a qualitative study carried out to investigate ethical implications generated in the process of care of HIV-positive pregnant women in the district context of a medium-sized town in the state of Santa Catarina. The data revealed the absence of a reference and counter-reference system that would be strong enough to guarantee integral care; negation of humanistic and physiological dimensions in the conducting of care; the presence of discriminatory processes; limitations in the production of ethical flows of the care network; submission of the right to narrative and a history of exclusion of the constitutional right to the guarantee of inviolability. The research emphasizes the need for an ethical dimension of the care to be assumed in the health care network, as a relational technology.

KEYWORDS: ethics; high-risk pregnant women; reference; counter-reference; care network; relational technology. 
UNIVALI

UNIVERSIDADE DO VALE DO ITAJAÍ

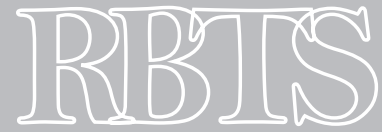

Revista Brasileira de Tecnologias Sociais 
A Constituição de 1988, voltada para a legitimação da democracia, considerou a descentralização um princípio norteador da nova forma de operacionalizar a atenção em saúde (BRASIL, 1988). Visando à regulação das ações e dos serviços, a Lei Orgânica da Saúde n. 8.080, sancionada pela Presidência da República em 1990, dispôs sobre a descentralização da gestão das ações e dos serviços de saúde para os municípios, a partir da regionalização e da hierarquização da rede de serviços de saúde do Sistema Único de Saúde (SUS) (BRASIL, 1990).

O processo de descentralização instituído foi atravessado pela criação do Programa Saúde da Família (PSF), ainda nos anos de 1990, como possibilidade estratégica de reordenamento da atenção básica, modelo de atenção à saúde representante da atenção primária à saúde no Brasil. A expansão desse Programa resultou na aprovação da Política Nacional de Atenção Básica (AB), em 2006, atualizada em 2011 pela Portaria n 2.488/GM, que apresentou a Estratégia Saúde da Família (ESF) como a principal estratégia da atenção básica. A iniciativa derivou da necessidade de o SUS construir um eixo ordenador dos fluxos em saúde, com base em um modelo ampliado de atenção, coordenado pela ESF, no qual o cuidado das pessoas seria o imperativo ético-político que organizaria a intervenção técnico-científica (BRASIL, 2011).

A partir dessas conquistas sociais, o Estado brasileiro começou a pensar em redes de atenção à saúde para garantir a atenção integral à saúde da sociedade. Em um esforço para integrar as ações e os serviços, de modo hierarquizado, outra estratégia foi apresentada: a disposição de um modelo em rede, preparado e responsável, como base estruturante de sistemas integrados (BRASIL, 2006).

Esse modelo em rede apresenta melhor capacidade de resposta às aspirações e às necessidades do coletivo ao apresentar-se como uma possibilidade de transformação das práticas nas realidades locais e regionais (MELLO et al., 2014). Os sistemas integrados, por sua vez, têm como principais características a oferta contínua de serviços por meio de pontos de atenção coordenados, a integração destes por meio de sistemas logísticos e a existência de uma população com necessidades definidas que seja responsabilidade do sistema de saúde (MENDES, 2011).

As redes regionalizadas de atenção à saúde geraram uma nova perspectiva de qualificação do cuidado, possibilitando o cuidado integral das necessidades de saúde da população por meio de dois componentes interdependentes que devem retroalimentar-se: referência e contrarreferência. Conformando um sistema entre os diferentes níveis de complexidade dos serviços, a referência e a contrarreferência são executadas em encaminhamentos mútuos entre os níveis de atenção à saúde. O encaminhamento de usuários a níveis especializados, quando requeridos pela $\mathrm{AB}$, corresponde à referência. $\mathrm{O}$ retorno à $\mathrm{AB}$, centro coordenador do cuidado integral (BRASIL, 2013), equivale à contrarreferência. Nesse sentido, o cuidado integral exige a formalização de fluxos responsáveis entre os níveis de atenção.

No entanto, em se tratando de um processo sistêmico que requer deliberação ética por parte dos atores sociais, nem sempre os valores realizados dos atores sociais envolvidos vão ao encontro da continência efetiva do processo de cuidado. É fato que muitas regiões ainda convivem com a inexistência de uma rede funcional e facilitadora do acesso ao cuidado integral, tendendo, de um lado, a desencadear fluxos migratórios desorganizados em busca de solução para problemas pessoais e, de outro, a manter excluído apreciável contingente populacional (BRASIL, 2009). 
Com relação ao cuidado prestado às gestantes soropositivas, a rede de atenção tem papel crucial e enfrenta desafios no tocante à redução de desfechos injustos e à qualificação do cuidado. A prática cotidiana tem revelado que muitas mulheres tomam conhecimento de que estão infectadas pelo HIV ao realizar o pré-natal, durante o parto ou no pós-parto. É uma descoberta dolorosa, pois, além de lidar com o próprio diagnóstico, elas se deparam com a possibilidade de transmissão do vírus ao filho.

Estudo desenvolvido com gestantes soropositivas para HIV demonstrou a importância de um ponto de escuta para a expressão da subjetividade e dos sentimentos desencadeados por discriminação, preconceito e exclusão (MATÃO et al., 2014). Essa necessidade tem exigido reflexões e ressignificações no âmbito da rede de atenção em saúde do SUS, pois a garantia de suporte necessário a essas mulheres é um direito conquistado socialmente e a ser desfrutado.

Em novembro de 2005, o Ministério da Saúde (MS) reuniu o Comitê Assessor para Recomendações de Profilaxia da Transmissão Vertical do HIV e Terapia Antirretroviral (TARV) em gestantes para revisar as recomendações de TARV e as demais condutas relacionadas à profilaxia da transmissão vertical do HIV. Parte dessa revisão se voltou para a redução de taxas de transmissão vertical, a partir da instituição da TARV para todas as gestantes a partir da $14^{\mathrm{a}}$ semana de gestação e de uma série de cuidados dirigidos à gestante (do pré-natal ao parto) e ao recém-nascido (BRASIL, 2010).

Essas questões integram o tema deste estudo, pautado em observações feitas no processo de trabalho em enfermagem no setor de infectologia de uma policlínica de uma cidade catarinense de grande porte. Nas atividades cotidianas, percebeu-se que, ao receberem o resultado positivo para o exame HIV, gestantes perdiam o vínculo com a Unidade Local de Saúde (ULS), passando a ser cuidadas pelo médico infectologista e pelo obstetra de alto risco. O processo de cuidado expunha a falta da contrarreferência ao transferir as ações da ESF para os profissionais da rede especializada. Nessa lógica, o foco não era o ser humano em um período singular da vida, com todas as peculiaridades que envolvem a gestação, mas sim a transmissão vertical do HIV. Foi a partir desse recorte de realidade que a pesquisa foi realizada, com o objetivo de conhecer implicações éticas geradas no processo de cuidado de gestantes soropositivas. O argumento do tex to dirigese para a importância de a dimensão ética (reflexão) do cuidado (ação política) ser reconhecida e assumida como uma tecnologia relacional pela rede de atenção à saúde do SUS, na medida em que a relação é o lócus de produção da vida.

\section{Metodologia}

Trata-se de uma pesquisa social empírica e compreensiva, de caráter exploratóriodescritivo, aprovada pelo Comitê de Ética da Universidade Federal de Santa Catarina (UFSC) no parecer nº 825/10, em consonância com as determinações da Resolução n 196/1996 do Conselho Nacional de Saúde (CNS). A investigação, realizada em um município de grande porte de Santa Catarina, teve como "interlocutores" (MINAYO; GUERREIRO, 2014, p. 1103) trabalhadores de uma ULS e profissionais do serviço de referência, selecionados a partir dos seguintes critérios de inclusão: ser profissional da ESF na ULS com maior número de notificações (na Vigilância Epidemiológica) de crianças expostas ao HIV e ser profissional referência para o atendimento a gestantes soropositivas no município.

A ULS eleita para o estudo compõe um distrito com outras unidades, policlínica, unidade de pronto atendimento e sede distrital. O campo de abrangência está dividido em quatro áreas e 
conta com três equipes de Saúde da Família (SF). O serviço de referência está localizado em uma policlínica municipal.

Uma vez autorizada pela Secretaria Municipal de Saúde, a pesquisa foi iniciada com o convite pessoal aos interlocutores em seus locais de trabalho. Os critérios para participação no estudo foram: disponibilidade de tempo para a entrevista, interesse em participar e assinatura do termo de consentimento livre e esclarecido. O anonimato dos participantes foi garantido, utilizando-se nomes de pedras preciosas para identificá-los.

O processo de produção do conhecimento se sustentou na consciência do pesquisador, apontado como o instrumento de análise mais indispensável em uma pesquisa compreensiva (DE MARTINO, 2009). Essa valoração foi ancorada no reconhecimento de que o encontro entre pesquisador e interlocutor é um espaço solidário de encontro entre sujeitos (LIMA; VERDI, 2009) e de produção de subjetividades dialeticamente ligadas à experiência do mundo real, isto é, vinculadas às experiências concretas, materiais e culturais (SEPPILLI apud LIMA, 2013). Subjetividades expressadas objetivamente, como estruturante[s] e constitutiva[s] da realidade (RAMOS; NITSCHKE; BORGES, 2009) investigada, na qual ambos os sujeitos, pesquisador e interlocutor, produzem-se, enquanto produzem conhecimento aproximado e construído (MINAYO; GUERREIRO, 2014).

Eleita como estratégia para a geração do material, a entrevista semiestruturada foi composta por dois blocos: o primeiro reuniu questões norteadoras da percepção dos interlocutores quanto ao cuidado às gestantes soropositivas no município e o segundo agregou uma situação-problema fictícia com o objetivo de apreender a percepção descrita em uma realidade contextualizada. As entrevistas foram realizadas em 2009.

O material foi gravado em áudio e transcrito com rigor acadêmico. Em seguida, foram feitas várias leituras atentas, a fim de extrair substantivos, verbos, adjetivos, imagem-objetivo, frases, ideias, modo de pensar-fazer, representativos de sentidos para os interlocutores. Tais núcleos de sentidos foram classificados e recortados em temas que se constituíram em unidades de registro que, tratadas e codificadas, resultaram na categoria de análise: "rede sem malha densa não abraça o cuidado”. A análise dos dados correspondeu a um processo hermenêutico-dialético, regulado pela abordagem ética e desenvolvido na interação do marco conceitual, material gerado e reflexividade (MINAYO; GUERREIRO, 2014)

\section{RESUlTAdos E DisCuSSÃO: REDE SEM MALHA DENSA NÃO ABRAÇA O CUIDADO}

A análise dos dados revelou a ausência de um sistema de referência e contrarreferência suficientemente denso para garantir o cuidado integral, direito conquistado na regulamentação da Lei Orgânica da Saúde:

[...] ela é encaminhada para a policlínica central, infectologista, e de lá […] a gente só vai saber o que aconteceu quando a criança nasce e começa a precisar de suporte local [para atender necessidades pontuais] [...] eu acho que dá perfeitamente para a gente fazer no local [o pré-natal $][\ldots]$ o problema é que os nossos funcionários estão despreparados. (CITRINO).

De acordo com a Portaria $n^{\circ}$ 1.020/GM/2013, a rede de atenção a gestantes portadoras de HIV deve assegurar o sistema de referência e contrarreferência, cabendo à atenção básica a 
coordenação do cuidado, o encaminhamento ao serviço de referência e o monitoramento do prénatal referenciado (BRASIL,2013).

O relato de Citrino sinaliza a falta de preparo de trabalhadores da ULS em relação ao processo de cuidado pré-natal voltado a mulheres soropositivas. Provavelmente, tem-se produzido um trabalho com gestantes dentro dos limites possíveis como reflexo de um modelo de formação que ainda confere supremacia à competência técnica em detrimento da força de trabalho requerida pelo SUS, necessária à operacionalização da rede de atenção em saúde do SUS. O direito ao cuidado integral na atenção básica é uma conquista da sociedade brasileira e, na mesma medida, a atenção especializada. O que se questiona atualmente é qual o perfil de profissional para o cuidado vem sendo formado, visto que a maior parte de currículos ainda fechados em universidades brasileiras aliena diferentes saberes e extravia a tão necessária formação humanística proporcionada por estudos mais gerais, resultando em trabalhadores despreparados para lidar com pessoas acometidas por doenças prevalentes no país (ALMEIDA FILHO, 2013).

O depoimento parece revelar que, uma vez constatada a infecção, o cuidado integral da gestante na $\mathrm{AB}$ se torna um mero coadjuvante da atenção especializada, entrando em cena somente para ancorar necessidades pontuais após o nascimento, provavelmente recebimento de leite, cesta básica e outros produtos. Esse processo ontológico da doença acaba hegemonizando a lógica da patogênese do modelo biomédico ao negar a importância de dimensões humanísticas e fisiológicas, reduzindo a gestante à prescrição retroviral, à assistência e à orientação quanto ao uso e aos efeitos da medicação. O efeito dessa prática se traduz em uma implicação ética na medida em que impulsiona processos discriminatórios e nega o direito ao cuidado integral.

A gestante soropositiva é um ser de direitos e de necessidades que se encontra em condições de normatividade alterada (CANGUILHEM, 2006). É um ser humano integral, uma síntese de múltiplas relações em seu contexto de vida, de modo que suas necessidades não são somente de ordem prescritiva, mas também de ordem simbólica, material e fisiológica. Considerando que a natureza de tais ordens contempla várias dimensões (econômica, política, cultural, social e orgânica), o reconhecimento da necessidade de formação qualificada para atuar na rede de atenção do SUS é uma exigência ética e política.

A tessitura de uma rede de atenção efetiva se dá na interface entre construtores das políticas públicas, trabalhadores qualificados e população usuária. É nessa interface que as condições devem ser dadas para que potencialidades éticas possam ser atualizadas em ato, emergindo nesse movimento de atualização o ser ético-político (KONDER, 2007). Esse ser é aquele reflexivo, que diante de várias possibilidades de ação escolhe a possibilidade mais razoável e prudente, justifica-a, renuncia às demais, responsabiliza-se por ela e a coloca em prática (CORTINA, 2003). Portanto, a dimensão ética e política deveriam ser exploradas na formação em saúde como um campo transversal.

Um dos papéis da enfermeira na atenção básica, no acolhimento da gestante, é o de respeitar os aspectos implicados nessa fase tão importante da vida da mulher, como sentimentos, emoções, mudanças do corpo, evolução da gestação, aumento da sensibilidade, cuidados com o bebê, sinais e sintomas do trabalho de parto. No entanto, o campo do acolhimento, na realidade da equipe contemplada nesta pesquisa, parece tensionado por um discurso performativo (BORDIEU, 1996), essencialista (centrado na contaminação pelo vírus, na adaptação ao vazio de contrarreferência e no reducionismo do espectro de ações da enfermagem), em detrimento do discurso universalizante, que considera o cuidado da gestante uma prática social e histórica (RAMOS et al., 2009): 
[...] ela não tem uma consulta de enfermagem regular assim, com tempo certo a

[…] quando ela chega na policlínica depois eventualmente ela passa por nós, ela depois não tem mais que passar pela gente entende? (Esmeralda). [ ...] eu acho que muita intercorrenciazinha que não tem a ver com o HIV, eles [da atenção básica] podem resolver. (ÁGATA).

Essas situações requerem trato ético, com vistas a um fazer engajado e transformador. Sendo a gestante soropositiva um ser de direitos e de necessidades, a ela está facultado o livre trânsito pela rede de atenção, pois é nesse fluxo entre atenção básica e especializada que ela poderá estabelecer relações suficientemente capazes de gerar plenitude na satisfação tanto de suas necessidades como daquelas do ser em gestação.

Entre os princípios do SUS, a integralidade é o que mais conduz "o desafio de realizar os valores de justiça, democracia e efetividade do acesso à saúde” (AYRES, 2009, p. 13-14). O percurso a ser desenvolvido entre o acesso e a garantia do cuidado integral exige a perspectiva da totalidade concreta (KOSIK, 1986.). Enquanto cada esfera da atenção em saúde não reconhecer o sistema e o ser humano a partir dessa visão, abraçando as especificidades do processo de viver, a integralidade tenderá à construção retórica. Descolar essa gestante, que tem dores e sabores e se encontra com a normatividade alterada, de uma primordial razão de ser da rede de atenção - o seu cuidado integral - poderá fomentar a fluidificação do potencial da rede em garantir o cuidado.

Uma das implicações da ausência de contrarreferência seria a impossibilidade de participação nos grupos de gestantes e de ter garantido o direito às ações do Núcleo de Apoio à Saúde da Família (NASF). É notório o papel dos grupos nessa fase da vida da mulher, na qual experiências podem ser compartilhadas, intercâmbios de sentimentos, incertezas, emoções podem ser maximizados. É evidente também a importância do Nasf como instrumento terapêutico singular e pedagógico em ações específicas do processo saúde-doença (BRASIL, 2008), mas este depoimento expressa outro cenário de práticas: “[ ...] nós não temos suporte no Nasf, nosso suporte é na policlínica” (CITRINO).

Sobre o tipo de parto e a profilaxia da transmissão vertical do HIV, o Ministério da Saúde recomenda a cesárea eletiva para casos em que a carga viral de gestantes soropositivas para o HIV é > 1000 cópias $/ \mathrm{ml}$ ou desconhecida. Tais recomendações são importantes e, quando divulgadas para as gestantes, conformam uma dimensão da garantia do cuidado integral. As recomendações do Ministério da Saúde são do âmbito da racionalidade instrumental, na medida em que seguem um parâmetro preconizado para a média das gestantes soropositivas quanto à susceptibilidade de transmissão vertical. Uma ação racional instrumental se transforma em uma ação racional ética se atravessada por uma ação racional orientada por valores, cujo sentido não está no resultado que se espera obter, mas na valoração das questões humanas que perpassam o contexto do processo humano (WEBER, 1993).

Dentre tais questões, está o direito de a gestante relatar sobre o tipo de parto que deseja e o dever de continência a esta expressão por parte do profissional. Esta relação direito-dever pode ser balizada pela realização do valor solidariedade no domínio da liberdade (LIMA; VERDI, 2009). Mas o depoimento de um interlocutor do sistema especializado revelou que este caso não requer diálogo, já que a recomendação ministerial sobre o tipo de parto está na dependência na quantidade de carga viral: [...] "se a carga estiver indetectável o parto é indicação obstétrica, então se tudo correr bem vai ser parto normal, não tem o que discutir [...] a não ser que tenha uma contraindicação obstétrica” (ÁGATA). 
A questão ética citada poderia ser fluidificada pela maximização de uma ética solidária de reconhecimento, na qual a responsabilização sobre a vida do outro configura um imperativo (LIMA; VERDI, 2015). Quando se projeta o olhar solidário para gestantes portadoras do vírus HIV, observa-se que é necessário oferecer meios para que essas mulheres desenvolvam sua autonomia e seu desejo de cuidar de si e do filho que estão gerando. Dessa forma, elas não estarão apenas seguindo um protocolo e toda a maratona de exames, de uso de antirretroviral, de enfrentamento aos possíveis efeitos colaterais da medicação. Na prática da solidariedade, tais especificidades serão parte do processo e, possivelmente, o exercício solidário poderá construir potencialidades para que mulheres (soropositivas ou não) sejam felizes nessa fase bela e singular de suas vidas. Independentemente de sua condição sorológica para o vírus HIV, toda mulher deve ser ouvida e orientada sobre todos os aspectos que envolvem a gestação, o parto e o pós-parto, a fim de que reconheça sua autonomia e seu protagonismo durante todo o processo.

A solidariedade pode ser realizada como um valor ético norteador da relação entre sujeito e profissional/equipe, partindo do entendimento de que essa prática é um espaço social de igualdade e de diferenças no qual um dos sujeitos é um agente social autorizado pelo saber científico para participar do processo do cuidado da pessoa que a ele se dirige em condições de vulnerabilidade (LIMA; VERDI, 2015). Não considerar que as condições ditas de vulnerabilidade estão inseridas em diversos domínios da vida, tornando impossível a visibilidade de aspectos socioeconômicos que afetam a adesão ao pré-natal, como o recurso para a passagem de ônibus, a alimentação do dia a dia, a falta no trabalho para o acompanhamento da saúde (limitada por muitas empresas), as mudanças climáticas (fatores que interferem na mobilidade). O efeito poderá ser a inscrição de culpabilizações sobre a pessoa que deveria ser o sentido de tudo, mas que é, no momento, o ser fragilizado: "A dificuldade vinha dela sabe, não do sistema porque ela era de difícil adesão, ela não fazia o tratamento” (QUARTZO).

Outra questão importante é o preconceito em torno de gestantes soropositivas. A atribuição de valores negativos a determinadas doenças é de natureza sócio-histórica e, ao longo do processo civilizatório, esse aspecto humano, indutor de diferenças individuais e sociais, desencadeou efeitos profundos e perversos, muitos dos quais ainda estão cristalizados na sociedade contemporânea. Nas questões que envolvem pessoas portadoras do HIV, a dinâmica da epidemia e suas especificidades impõem desafios à construção do conhecimento e ao campo de intervenção, porém está no uso do referencial ético o maior dos desafios (KOYAMA, 2008). Os depoimentos de Citrino e Jaspe reforçam a importância de resgate de valores humanos:

[...] o único problema que eu vejo é na minha equipe, a questão da sensibilização de todas as pessoas [...] de repente alguém tem medo de se contaminar porque está fazendo uma injeção nela (Citrino). [...] a gente faz o encaminhamento pro atendimento do alto risco, acho que é o único caminho que a gente tem. (JASPE).

No caso de gestantes portadoras do HIV, há a exigência de tomada de atitudes adequadas e, em tempo hábil, no desenho estratégico da referência/contrarreferência do sistema que, cotidianamente, deve abrir portas para o exercício ético do cuidado a partir do combate ao preconceito. Não é tarefa fácil superá-lo em um modelo de sociedade que insiste em cultivar as liberdades individuais e em banalizar a utopia de enfrentamento a questões coletivas: uma sociedade intolerante aos prováveis efeitos do uso da ideia de risco (BAUMAN, 2000).

O enquadramento de mulheres soropositivas em compartimentos sociais coletivos discriminatórios, os chamados grupo de risco, não é uma escolha que se faz em nível micro, mas 
uma construção cultural da sociedade contemporânea de risco, em cujo desenho a ideia de risco controla a existência do hoje. A sociedade de risco é formada por individualidades individualizadas, dispostas em rede. O que interessa para essa sociedade não é acordar/negociar o bem comum e qualificar a rede, mas ser parte desta e alcançar soluções não na sujeição histórica, mas na instantaneidade do próprio ser (BECK, 2011).

Ainda que pese a força dessa subformação neoliberal (de risco), plasmada sobre a sociedade de classes (LIMA, 2013), faz-se necessário investir em redes de atenção que equacionem crescimento econômico e equidade, pois somente estas estariam investindo nos efeitos gerados no histórico cenário de desigualdades sociais, lócus de produção da ideia de risco e, por consequência, da problematização do preconceito. Tais políticas poderiam gerar fraturas no arcabouço da sociedade de risco, rumo à construção de uma sociedade coesa (WANDERLEY, 2008).

[...] tem preconceito até de colega que a gente sabe que tem, enfermagem tem, de dentista tem [...] pra mim paciente HIV e não ter HIV é tudo igual, mas infelizmente a gente vê que não assim entre os colegas (Ágata). [...] o único problema que eu vejo é na minha equipe, a questão da sensibilização de todas as pessoas; nutrição, odonto, morre de medo de qualquer bichinho extra. (CITRINO).

Estudo realizado em 2007 para apreender as múltiplas significações sobre o uso de equipamentos de proteção individual (EPI) pela equipe de referência para pessoas portadoras de tuberculose, em uma Unidade Local de Saúde do mesmo município contemplado neste estudo, mostrou o preconceito como uma inscrição latente, gerado na falta de consistência da base epistemológica do cuidado com pessoas portadoras de tuberculose. As relações se mostraram atravessadas pelo medo de se contaminar, hegemonizando a exclusão com o discurso também de sensibilização: “[ .... a gente faz é a sensibilização [...] vocês podem passar a tuberculose pra gente que tá aqui dentro [...] tem criança, tem gestante [...]” (CARVALHO et al., 2010, p. 150).

A mesma pesquisa revelou uma implicação ética ligada ao sigilo dos dados pessoais das gestantes portadoras de HIV no espaço de atuação de agentes comunitários de saúde, trabalhadores da equipe de SF: “[ [... a agente comunitária vai ali e alguém vai ficar sabendo, ela comenta ou alguém comenta no bairro […]”.

As atividades de ACS carregam a peculiaridade de esses profissionais residirem próximo ao local de trabalho e, por consequência, estabelecerem relações sociais mais estreitas com as pessoas por eles visitadas e cuidadas. Contudo, a existência de um maior envolvimento com o tecido social não lhes confere a prerrogativa de agenciar uma trajetória de exclusão do direito constitucional de garantia da inviolabilidade da intimidade, vida privada e imagem de pessoas da comunidade (BRASIL, 1988). Estudo qualitativo sobre ACS e privacidade de informações de usuários, realizado com coordenadores e trabalhadores de PSF em dois distritos de saúde de São Paulo, revelou a importância fundamental de ACS na continência do sofrimento das pessoas: um sofrimento muito frequentemente gerado no vazio de relações de amizade e afeto. No entanto, o estudo sinalizou que o contato frequente com as pessoas favorece a revelação de elementos da esfera íntima (FORTES; SPINETTI, 2004).

\section{CONSIDERAÇÕES}

A pesquisa buscou conhecer implicações éticas geradas no processo de cuidado de gestantes soropositivas de um município catarinense de grande porte. Foi realizada com trabalhadores da 
Unidade Local de Saúde Distrital com maior número de notificações de crianças expostas ao HIV junto à Vigilância Epidemiológica e com trabalhadores de referência.

Analisados a partir da categoria "Rede sem malha densa não abraça o cuidado", os dados revelaram como implicações éticas: ausência de um sistema de referência e contrarreferência suficientemente denso para garantir o cuidado integral, negação das dimensões humanísticas e fisiológicas na condução do cuidado, supremacia de processos discriminatórios em detrimento do direito universal ao cuidado integral, limitação no direito de a gestante transitar pela rede de atenção mediante fluxos éticos, submissão do direito de narrar o seu processo saúde-doença frente à supremacia de aplicação de recomendações ministeriais e uma trajetória de exclusão do direito constitucional de garantia da inviolabilidade da vida privada.

O cuidado integral se apresentou como um mero coadjuvante da atenção especializada e as ações se mostraram tensionadas por um discurso performativo centrado na contaminação pelo vírus e no reducionismo do horizonte de ações em saúde. As recomendações do Ministério da Saúde, voltadas para a susceptibilidade de transmissão vertical, estreitaram o espaço de diálogo, tão caro em um processo gestacional. Enquadradas no chamado grupo de risco, as gestantes portadoras de HIV refletiram a construção cultural da sociedade contemporânea de risco, em cujo desenho a ideia de risco controla a existência do hoje.

A pesquisa faz um chamado para a exigência de tessitura solidária de um sistema de referência e contrarreferência, no âmbito do cuidado a gestantes portadoras de HIV, a partir da realização de valores coletivos suficientemente capazes de conduzir um fluxo ético entre os pontos de atenção, bem como para a importância da formação ética e política em saúde.

\section{REFERÊNCIAS}

ALMEIDA FILHO, N. M. Contextos, impasses e desafios na formação de trabalhadores em saúde coletiva no Brasil. Cienc Saude Colet, v. 18, n. 6, p. 1677-1682, 2013.

AYRES, J.R de C. M. Organização das ações de atenção à saúde: modelos e práticas. Saúde e Sociedade, v. 18, n. 2, p. 11-23, 2009.

BAUMAN, Z. Em busca da política. Rio de Janeiro: Jorge Zahar, 2000.

BECK, U. La società del rischio. Urbino: Carocci, 2011.

BOURDIEU, P. A economia das trocas linguísticas. São Paulo: Edusp, 1996.

BRASIL. Constituição da República Federativa do Brasil. Brasília: Senado Federal, 1988.

BRASIL. Ministério da Saúde. Acolhimento e classificação de risco nos serviços de urgência. Brasília: Ministério da Saúde, 2009.

BRASIL. Ministério da Saúde. Diretrizes para a programação pactuada e integrada da assistência à saúde. Brasília: Ministério da Saúde, 2006.

BRASIL. Lei n 8.080, de 19 de setembro de 1990. Dispõe sobre as condições para a promoção, proteção e recuperação da saúde, a organização e o funcionamento dos serviços correspondentes e dá outras providências. Brasília, 1990.

BRASIL. Ministério da Saúde. Portaria $n^{\circ}$ 1.020, de 29 de maio de 2013. Institui as diretrizes para a 
organização da atenção à saúde na gestação de alto risco e define os critérios para a implantação e habilitação dos serviços de referência à atenção à saúde na gestação de alto risco, incluída a casa de gestante, bebê e puérpera (CGBP), em conformidade com a Rede Cegonha. Brasília: Ministério da Saúde, 2013.

BRASIL. Ministério da Saúde. Portaria n 154, de 24 de janeiro de 2008. Cria os núcleos de apoio à saúde da família - NASF. Brasília: Ministério da Saúde, 2008.

BRASIL. Ministério da Saúde. Portaria n².488, de 21 de outubro de 2011. Aprova a política nacional de atenção básica, estabelecendo a revisão de diretrizes e normas para a organização da atenção básica, para a estratégia saúde da família (ESF) e o programa de agentes comunitários de saúde (PACS). Brasília, 2011.

BRASIL. Ministério da Saúde. Recomendações para profilaxia da transmissão vertical do HIV e terapia anti-retroviral em gestantes. Brasília: Ministério da Saúde, 2010.

CANGUILHEM, G. O normal e o patológico. São Paulo: Forense Universitária, 2006.

CARVAlHO C. C. de; CARVALhO JUNiOR, D. C. de; VAlENTE, L. L., SOUZA, M.G.F. de; LiMA, R. de C. G. S.; LACERDA, J. T. A biossegurança e o estigma do portador de tuberculose: o grande desafio!. In: BUCHELE, F.; COELHO, E. B. S. C. (org.). A formação em saúde da família. Florianópolis: UFSC, 2010. p. 139-154.

CORTINA, A. O fazer ético: guia para a educação moral. São Paulo: Moderna, 2003.

DE MARTINO, E. La terra del rimorso. Milano: Il Saggiatore, 2009.

FORTES, P. A. de C.; SPINETTI, S. R. O agente comunitário de saúde e a privacidade das informações de usuários. Cadernos de Saúde Pública, v. 20, n. 5, p. 1328-1333, 2004.

GARCIA, S; KOYAMA, M. A. H. Estigma, discriminação e HIV/Aids no contexto brasileiro, 1998 e 2005. Revista de Saúde Pública, v. 42, n. 1, p. 72-83, 2008.

KONDER, L. O que é dialética. São Paulo: Brasiliense, 2007.

KOSIK, K. Dialética do concreto. Rio de Janeiro: Paz e Terra, 1986.

LIMA, R. de C. G. S. Movimento atenção primária à saúde como um produto da hegemonia: análise das assembleias mundias de saúde de 1948 a 1978. Tese (Doutorado em Saúde Coletiva) - Universidade Federal de Santa Catarina, Florianópolis. 2013.

LIMA, R. de C. G. S; VERDI, M. I. M. A solidariedade na medicina de família no Brasil e na Itália: refletindo questões éticas e desafios contemporâneos. Interface, v. 13, n. 29, p. 271-283, 2009.

LIMA, R. de C. G. S; VERDI, M. I. M. Capitalismo e ontologia da bioética: o processo de trabalho de médicos de família na Itália. Trabalho, Educação e Saúde, v. 13, n. 2, p. 323-341, 2015.

MATÃO, M. E. L.; MIRANDA, D. B. de; FREITAS, M. I. de F.; CAMPOS, P. H. F. Representações sociais da gestação para mulheres soropositivas. Revista de Enfermagem da UFPE, v. 8, n. 5, p. 12011212. 2014.

MELLO, A. L. S. F. de; ANDRADE, S. R. de; MOYSÉS, S. J.; ERDMANN, A. L. Saúde bucal na rede de atenção e processo de regionalização. Cienc Saude Colet, v.19, n. 1, p. 205-2 14, 2014.

MENDES, E. V. As redes de atenção à saúde. Brasília: Organização Pan-Americana da Saúde, 2011.

MINAYO, M. C. de S.; GUERRIERO, I. C. Z. Reflexividade como éthos da pesquisa qualitativa. Cienc Saude Colet, v. 19, n. 4, p. 1103-1112, 2014. 
RAMOS, F. R. S.; NITSCHKE R. G.; BORGES, L. M. A bioética nas contingências do tempo presente: a crítica como destino? Texto Contexto Enfermagem, v. 18, n. 4, p. 788-796, 2009.

WANDERLEY, L. E. W. A questão social no contex to da globalização: o caso latino-americano e caribenho. In: CASTEL, R; WANDERLEY, L E. W.; BELFIORE-WANDERLEY, M. (org.). Desigualdade e a questão social. São Paulo: Educ, 2008. p. 55-166.

WEBER, M. Metodologia das ciências sociais. São Paulo: Cortez, 1993. 